\title{
The prognostic role of nutrition risk score (NRS) in patients with metastatic or recurrent esophageal squamous cell carcinoma (ESCC)
}

\author{
Xia Zhou ${ }^{2}$, Guo-Qin Qiu ${ }^{1}$, Wu-An Bao ${ }^{1}$ and Dan-Hong Zhang ${ }^{1}$ \\ ${ }^{1}$ Department of Radiotherapy, Zhejiang Cancer Hospital, Hangzhou, Zhejiang, China \\ ${ }^{2}$ Department of Radiation Therapy, Zhejiang Cancer Hospital, Hangzhou, Zhejiang, China \\ Correspondence to: Xia Zhou, email: zhouxia2008@hotmail.com \\ Keywords: esophageal squamous cell carcinoma, metastasis, nutrition, chemotherapy \\ Received: August 26, $2016 \quad$ Accepted: July 28, $2017 \quad$ Published: August 24, 2017 \\ Copyright: Zhou et al. This is an open-access article distributed under the terms of the Creative Commons Attribution License 3.0 \\ (CC BY 3.0), which permits unrestricted use, distribution, and reproduction in any medium, provided the original author and source \\ are credited.
}

\section{ABSTRACT}

The purpose of this study was to elucidate the prognostic value of nutritional risk score (NRS) in patients with metastatic or recurrent ESCC. A total of 187 patients who undergoing $\mathrm{S} 1$ based or paclitaxel based salvage chemotherapy were enrolled in this retrospective study. Nutritional status was evaluated by NRS. The relationship between NRS and clinicopathological variables and post-treatment outcomes were assessed by univariate and multivariate analysis. NRS was significantly associated with weight loss $(P<0.001)$, BMI $(P<0.001)$, chemotherapy regimens $(P=0.038)$ and treatment response $(P=0.013)$. The Kaplan-Meier survival curves indicated that patients with NRS $\geq 3$ had worse overall survival (OS) compared to patients with NRS $<3(P<0.001)$. Multivariable regression revealed that weight loss, NRS and treatment response were three prognostic factors $(P<0.05)$. These results suggest that NRS is a promising indicator of poor prognosis in patients with metastatic or recurrent ESCC who received $\mathrm{S} 1$ based or paclitaxel based salvage chemotherapy.

\section{INTRODUCTION}

Esophageal cancer remains the eighth most commonly diagnosed cancer worldwide. Although the five-year overall survival rate for patients with localized disease approaches $85 \%$ [1], the survival rate for metastatic or recurrent disease is only 5\% [2]. Most patients are died of nutritional problem that leading to metabolic and physiological changes.

Esophageal squamous cell carcinoma (ESCC) is considered to be the predominant type in eastern Asia countries, with increased incidence recently [3]. Patients are often presented with obstructive symptoms, such as dysphagia and unintended weight loss. Furthermore, the psychological influence of cancer diagnosis and treatment can cause low mood or depression, which also reduce patients' appetite [4]. Most patients could be affected by malnutrition during diagnosis, cancer treatment and follow-up. A consensus exists that weight loss is one of the most important criteria for malnutrition. Weight loss, poor life-style associated factor, is a common symptom in $60 \%$ of patients before diagnosis [5]. Significant weight loss resulted in systemic inflammation [6], higher rate of treatment complications and lower quality of life. Many studies reported that weight loss is associated with cancer recurrence in gastric cancer [7] and breast cancer [8]. However, weight loss alone does not identify the full effect of malnutrition on physical function [9] and is not a perfect prognostic factor [10]. Nutrition risk score (NRS) is a novel method for distinguishing high risk patients who will suffer from malnutrition and related with survival in gastric cancer [11]. Therefore, we were interested in that if this new method can be used in metastatic or recurrent ESCC patients who received palliative chemotherapy.

The aim of this study was investigate the association between NRS and other nutrition variables and the prognostic value of NRS in patients with metastatic or recurrent ESCC. 


\section{RESULTS}

\section{Patients' characteristics}

A total of 187 patients with metastatic or recurrent ESCC were analyzed. Baseline characteristics were presented in Table 1. Most patients were male (61.5\%) with the median age of 61 years (range: 38-78 years). Most patients $(66.8 \%, 125 / 187)$ had metastatic disease and 13 patients $(7.0 \%)$ both had metastatic and recurrent disease. More than half of the patients $(62.6 \%, 117 / 187)$ had experienced subtotal transthoracic esophagectomy and regional lymphadenectomy with curative intent, and other 70 patients $(37.4 \%)$ had experienced radical radiotherapy. Most patients $(57.8 \%)$ received S1 based chemotherapy and the remaining patients $(41.2 \%)$ received paclitaxel based chemotherapy. All procedures performed in studies involving human participants were in accordance with the ethical standards of the institutional research committee. This study was approved by the institutional review board of the hospital. Informed consent was obtained from all patients included in the study.

\section{Relationship between NRS and clinical features}

According to NRS, 52.4\% $(n=98)$ had a score $\geq 3$. The median NRS for all patients was 3. NRS was significantly associated with weight loss $(\mathrm{P}<0.001)$, BMI $(\mathrm{P}<0.001)$, chemotherapy regimens $(\mathrm{P}=0.038)$ and treatment response $(\mathrm{P}=0.013)$, whereas there was no significant association between gender $(\mathrm{P}=0.495)$, age $(\mathrm{P}=0.722)$, first line treatment $(\mathrm{P}=0.924)$ and tumor location $(\mathrm{P}=0.722)$. Correlation of NRS with $\mathrm{BMI}$, weight loss, serum albumin level, hemoglobin and tumor markers are presented in Table 2. Spearman's correlation revealed that NRS had a positive correlation with weight loss $(\mathrm{P}<0.001)$ and serum albumin level $(\mathrm{P}<0.001)$.

\section{Association of NRS with survival}

After a median follow-up duration of 23 months, the estimate 1-year and 2-year overall survival rates in all patients were $42.3 \%$ and $9.4 \%$, respectively. One hundred and sixty-four patients died due to tumor progression or malnutrition. Weight loss, treatment response and NRS were significantly related with OS (Table 3 ). The KaplanMeier survival curves indicated that patients with NRS $\geq 3$ had worse OS compared to patients with NRS $<3$ ( $\mathrm{P}<0.001$, Figure 1). In further analyses, NRS $\geq 3$ was significantly associated with shorter OS for patients who received S1 based chemotherapy ( $\mathrm{P}=0.005$, Figure $2 \mathrm{~A}$ ) and patients who received paclitaxel based chemotherapy $(\mathrm{P}<0.001$, Figure 2B). One-year survival probability was $28.7 \%$ for NRS $\geq 3$ patients versus $54.2 \%$ for NRS $<3$ patients with $\mathrm{S} 1$ based chemotherapy, and $23.9 \%$ for NRS $\geq 3$ patients versus $60.0 \%$ for NRS $<3$ patients with paclitaxel based chemotherapy. Similarly, NRS $\geq 3$ was significantly associated with shorter OS for female patients $(\mathrm{P}<0.001$, Figure $3 \mathrm{~A})$ and male patients $(\mathrm{P}=0.016$, Figure $3 \mathrm{~B})$.

Then we performed multivariable regression using a Cox proportional hazards models revealed that weight loss, NRS and treatment response were three prognostic factors in patients with metastatic or recurrent ESCC $(\mathrm{P}<0.05)$. Patients with NRS $\geq 3$ had an elevated risk of death compared to those with NRS $<3$. The hazard ratio was 2.14 (95\% confidence interval [CI] 1.25-3.68) for death (Table 4).

\section{NRS in the validation cohort}

When the cutoff value of 3 was used in the validation cohort, $68(51.5 \%)$ of the ESCC patients were observed to have NRS $\geq 3$. The age distribution, tumor location, treatment response, and NRS were well balanced between the two patients' cohorts $(\mathrm{P}>0.05)$. The patients in the validation cohort with $\mathrm{NRS} \geq 3$ exhibited decreased OS $(\mathrm{P}=0.016)$ compared with the patients who had NRS $<3$ (Figure 4). The multivariate $\mathrm{COX}$ regression analysis showed that NRS $\geq 3$ and treatment response were independent predictors (Table 4).

\section{DISCUSSION}

In this present study, we investigated NRS in metastatic or recurrent ESCC and its correlation with prognosis. Our data demonstrated that NRS was significantly associated with weight loss and serum albumin level. NRS was an independent prognostic factor related with overall survival in metastatic or recurrent ESCC. As predicted, the OS was better for patients with $\mathrm{NRS}<3$ than for patients with NRS $\geq 3$.

Currently, the TNM staging system is a standard method to predict patients' prognosis. However, clinicians need an accurate tool to manage the treatment and predict survival when patients developed distant metastasis or local-regional recurrence. Tumor markers, such as CEA, SCC and CYFRA2-11, are not precisely associated with outcome in metastatic or recurrent ESCC patients [12]. In our study, tumor markers (CEA, CA125, CA199 and CA724) were not associated with overall survival according to univariate analysis $(\mathrm{P}>0.05)$. Several studies reported that the nutritional and immunologic conditions of patients could influence the post-operative complications and outcome with cancer [13-15]. NRS, calculated based on patients' weight loss and BMI, is a significant predictor for malnutrition according to Cox et al' report [16]. The nutritional status was also shown recently to be an indicator for complications in patients with esophageal cancer [17, 18]. Early nutritional support could significantly reduce severe complications which related with high morbidity, such as pulmonary complications and anastomotic leakage [19]. Although 
Table 1: The nutrition risk score (NRS) and clinicopathological characteristics in 187 metastatic or recurrent ESCC

\begin{tabular}{|c|c|c|c|c|}
\hline \multirow[t]{2}{*}{ Variables } & \multirow[t]{2}{*}{ Patients (n) } & \multicolumn{2}{|c|}{ NRS } & \multirow[t]{2}{*}{$\mathbf{P}$} \\
\hline & & $<3$ & $\geq \mathbf{3}$ & \\
\hline \multicolumn{5}{|l|}{ Gender } \\
\hline Female & 72 & $32(44.4)$ & $40(55.6)$ & 0.495 \\
\hline Male & 115 & $57(49.6)$ & $58(50.4)$ & \\
\hline \multicolumn{5}{|l|}{ Age (years) } \\
\hline$\leq 60$ & 92 & $45(48.9)$ & $47(51.1)$ & 0.722 \\
\hline$>60$ & 95 & $44(46.3)$ & $51(53.7)$ & \\
\hline \multicolumn{5}{|l|}{ First line treatment } \\
\hline Radiotherapy & 70 & $33(47.1)$ & 37 (52.9) & 0.924 \\
\hline Surgery & 117 & $56(47.9)$ & $61(52.1)$ & \\
\hline \multicolumn{5}{|l|}{ Weight loss } \\
\hline Yes & 90 & $6(6.7)$ & $84(93.3)$ & $<0.001$ \\
\hline No & 97 & $83(85.6)$ & $14(14.4)$ & \\
\hline \multicolumn{5}{|l|}{ Tumor location } \\
\hline Upper and middle & 92 & $45(48.9)$ & $47(51.1)$ & 0.722 \\
\hline Lower & 95 & $44(46.3)$ & $51(53.7)$ & \\
\hline \multicolumn{5}{|l|}{ Serum albumin level } \\
\hline$\leq 42.1$ & 88 & $38(43.2)$ & $50(56.8)$ & 0.255 \\
\hline$>42.1$ & 99 & $51(51.5)$ & $58(48.5)$ & \\
\hline \multicolumn{5}{|l|}{ BMI } \\
\hline$\leq 20.4$ & 95 & $30(31.6)$ & $65(68.4)$ & $<0.001$ \\
\hline$>20.4$ & 92 & $59(64.1)$ & $33(35.9)$ & \\
\hline \multicolumn{5}{|l|}{ Failure type } \\
\hline Metastasis & 125 & $55(44.0)$ & $70(56.0)$ & 0.294 \\
\hline Recurrent & 49 & $28(57.1)$ & $21(42.9)$ & \\
\hline $\begin{array}{l}\text { Metastasis and } \\
\text { recurrent }\end{array}$ & 13 & $6(46.2)$ & $7(53.8)$ & \\
\hline \multicolumn{5}{|l|}{$\begin{array}{l}\text { Chemotherapy } \\
\text { regimens }\end{array}$} \\
\hline S1 & 108 & $44(40.7)$ & $64(59.3)$ & 0.038 \\
\hline Paclitaxel & 79 & $45(57.0)$ & $34(43.0)$ & \\
\hline \multicolumn{5}{|l|}{ Treatment response } \\
\hline $\mathrm{CR}+\mathrm{PR}$ & 67 & $40(59.7)$ & $27(40.3)$ & 0.013 \\
\hline $\mathrm{SD}+\mathrm{PD}$ & 120 & $49(40.8)$ & $71(59.2)$ & \\
\hline \multicolumn{5}{|l|}{ Second line treatment } \\
\hline Yes & 62 & $30(48.4)$ & $32(51.6)$ & 0.835 \\
\hline No & 124 & $58(46.8)$ & $66(53.2)$ & \\
\hline
\end{tabular}


Table 2: Correlation of NRS with nutritional variables and tumor markers

\begin{tabular}{lcc}
\hline Variables & & NRS \\
\cline { 2 - 3 } & Correlation & P \\
\hline BMI & -0.085 & 0.247 \\
Weight loss & 0.743 & $<0.001$ \\
Serum albumin level & -0.396 & $<0.001$ \\
Hemoglobin & -0.095 & 0.196 \\
Red blood cell count & -0.011 & 0.884 \\
CEA & 0.112 & 0.140 \\
CA125 & -0.057 & 0.475 \\
CA199 & -0.039 & 0.602 \\
CA724 & -0.084 & 0.368 \\
\hline
\end{tabular}

past studies have shown important findings for NRS, its clinical significance has not yet been clarified in patients with metastatic or recurrent ESCC. In the present study, NRS was significantly related with treatment response and multivariate analysis revealed that NRS, not serum tumor markers and BMI, was an independent indicator for prognosis. The combination of TNM stage and NRS may be a more effective tool for predicting treatment response and outcome in patients with metastatic or recurrent ESCC. Physicians should investigate patients' nutritional status, not only based on serum albumin level or BMI, but also on NRS. Patients with higher NRS (NRS $\geq 3$ ) should receive close post-treatment follow-up.

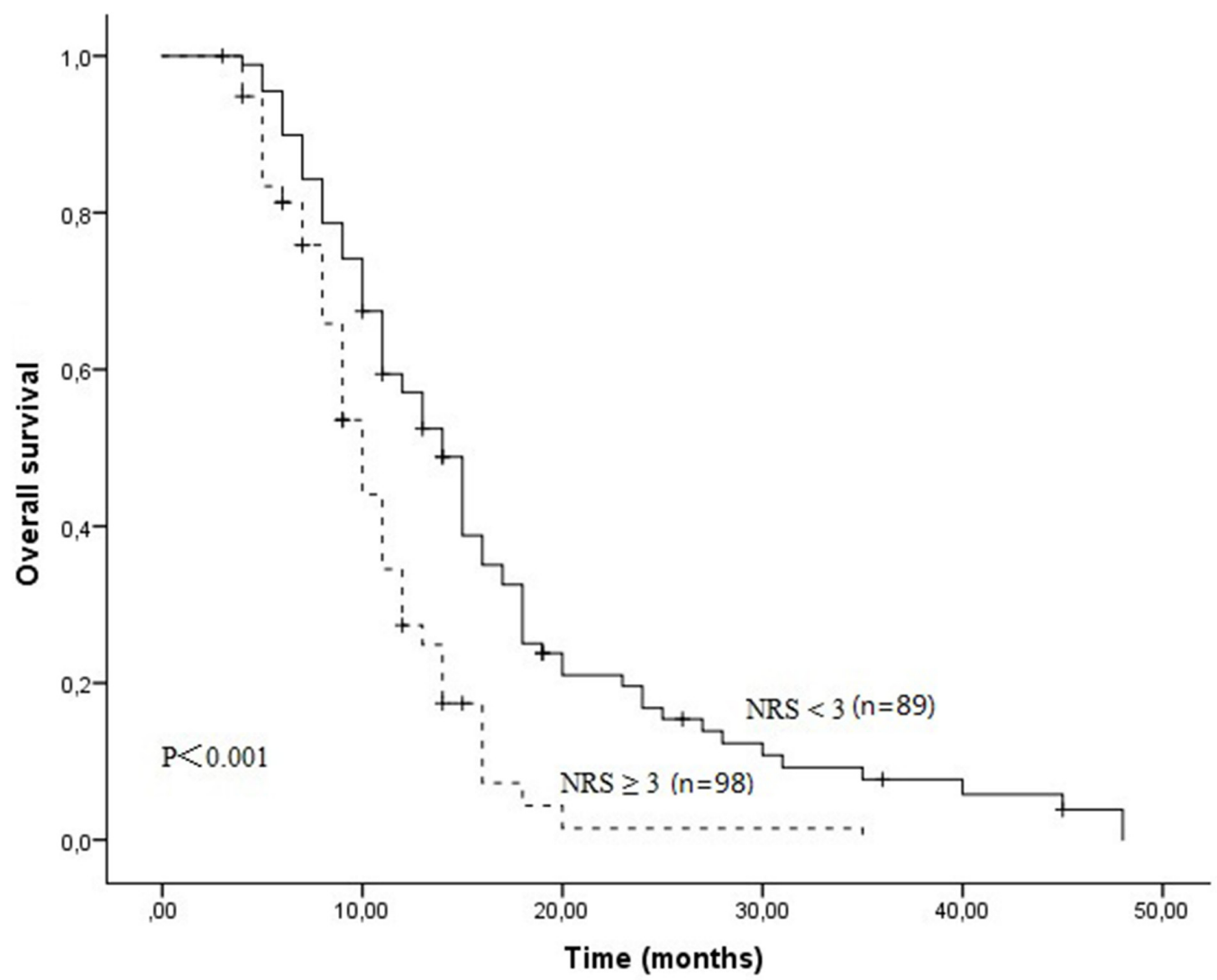

Figure 1: The Kaplan-Meier survival curves indicated that patients with NRS $\geq 3$ had worse OS compared to patients with NRS $<3$ (11.0 months Vs 14.0 months, $\mathrm{P}<0.001)$. 
Another important result of this study was that in patients with metastatic or recurrent ESCC, salvage chemotherapy with paclitaxel-based regimens could slightly improve overall survival $(\mathrm{P}=0.071)$. In Yang et al' report, chemotherapy with paclitaxel-based regimens demonstrated higher efficacy with less toxicity in patients with ESCC compared with the fluorouracil based regimens [20]. The median PFS in patients received paclitaxelbased regimens were significantly longer than in patients received S1-based regimens ( $13.0 \mathrm{~m}$ Vs $6.5 \mathrm{~m}, \mathrm{P}=0.034)$. In our study, the estimate 2 -year OS rates were $16.7 \%$ and $5.9 \%$ in patients received paclitaxel-based regimens and
$\mathrm{S} 1$-based regimens. It seems in salvage chemotherapy using paclitaxel-based regimens was a promising treatment in patients with metastatic or recurrent ESCC. However, further large scale randomized clinical trials are needed to confirm this result.

There are several limitations of this study. The major limitation is that the information of post-treatment local recurrence or metastasis was insufficient. One of the least convincing things in this study are lack the data of disease free survival, although overall survival is the standard indicator in the cancer prognosis study. Another limitation is the number of study samples was relatively small.
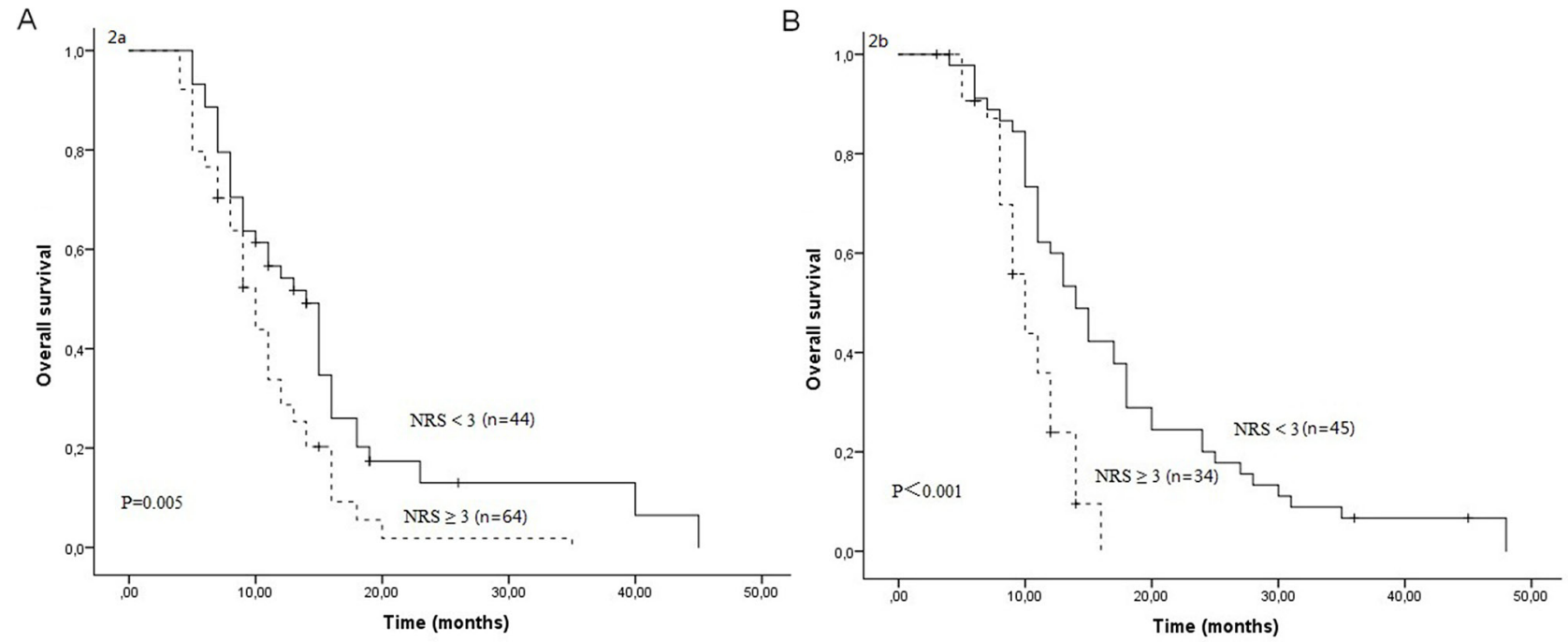

Figure 2: Overall survival curves between NRS $\geq 3$ and NRS $<3$ in patients who received S1 based chemotherapy (A) and in patients who received paclitaxel based chemotherapy (B).

A

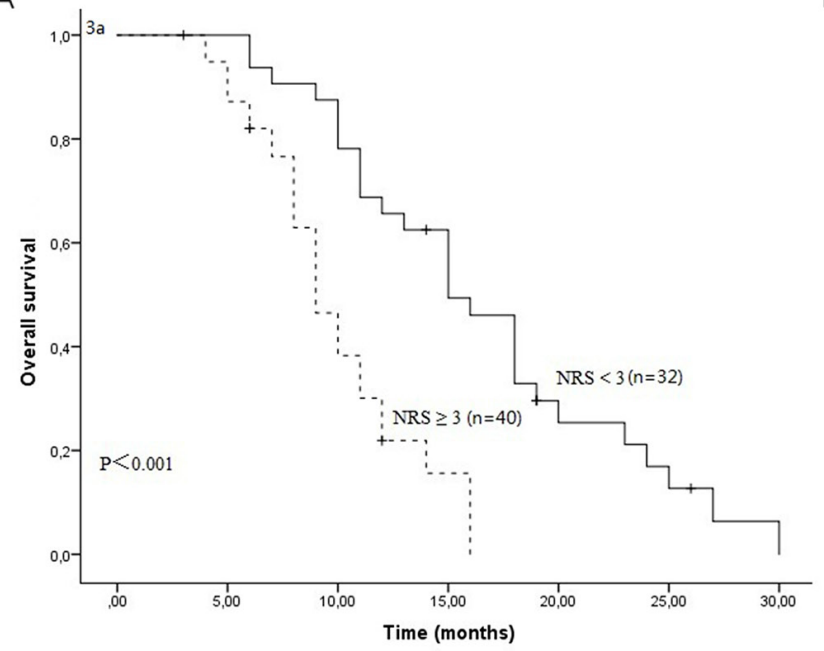

B

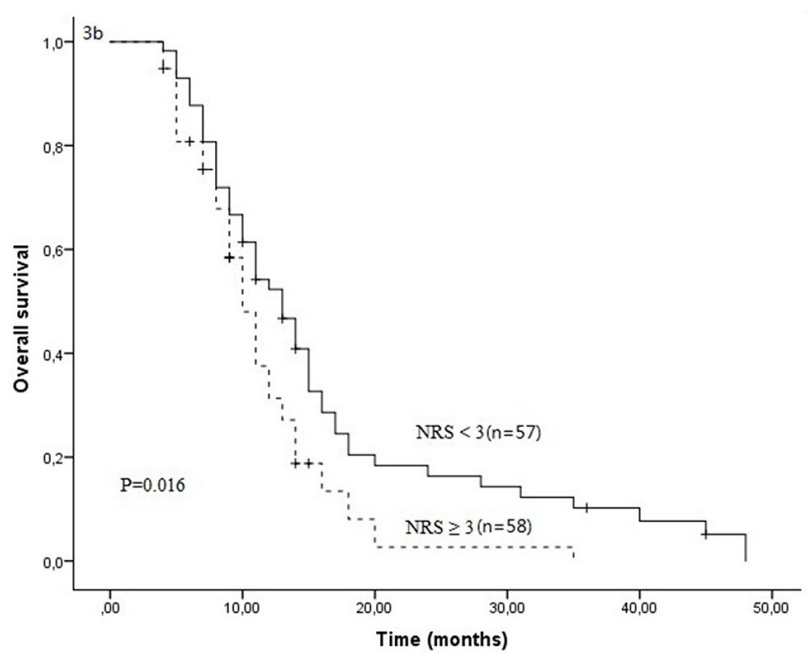

Figure 3: Overall survival curves between $N R S \geq 3$ and NRS $<3$ in female patients (A) and in male patients (B). 
Table 3: Prognostic factors for OS by univariate analysis for patients with metastatic or recurrent ESCC (n=187)

\begin{tabular}{|c|c|c|c|c|c|}
\hline Variables & Patients (n) & Median OS (months) & 1-year OS rate $(\%)$ & 2-year OS rate (\%) & $\mathbf{P}$ \\
\hline \multicolumn{6}{|l|}{ Gender } \\
\hline Female & 72 & 12.0 & 48.0 & 9.2 & 0.956 \\
\hline Male & 115 & 12.0 & 46.1 & 12.2 & \\
\hline \multicolumn{6}{|l|}{ Age (years) } \\
\hline$\leq 60$ & 92 & 14.0 & 53.9 & 13.0 & 0.314 \\
\hline$>60$ & 95 & 11.0 & 40.3 & 8.8 & \\
\hline \multicolumn{6}{|l|}{$\begin{array}{l}\text { First line } \\
\text { treatment }\end{array}$} \\
\hline Radiotherapy & 70 & 11.0 & 46.1 & 10.3 & 0.711 \\
\hline Surgery & 117 & 11.0 & 41.7 & 8.8 & \\
\hline \multicolumn{6}{|l|}{ Weight loss } \\
\hline Yes & 90 & 13.0 & 38.9 & 4.2 & 0.012 \\
\hline No & 97 & 11.0 & 53.4 & 17.0 & \\
\hline \multicolumn{6}{|l|}{ Tumor location } \\
\hline $\begin{array}{l}\text { Upper and } \\
\text { middle }\end{array}$ & 92 & 11.0 & 42.1 & 7.5 & 0.203 \\
\hline Lower & 95 & 13.0 & 51.3 & 14.1 & \\
\hline \multicolumn{6}{|l|}{$\begin{array}{l}\text { Serum albumin } \\
\text { level }\end{array}$} \\
\hline$\leq 42.1$ & 88 & 11.0 & 43.2 & 11.6 & 0.642 \\
\hline$>42.1$ & 99 & 14.0 & 50.2 & 10.5 & \\
\hline \multicolumn{6}{|l|}{ BMI } \\
\hline$\leq 20.4$ & 95 & 11.0 & 42.2 & 9.4 & 0.789 \\
\hline$>20.4$ & 92 & 13.0 & 51.6 & 13.2 & \\
\hline \multicolumn{6}{|l|}{ Tumor length } \\
\hline$\leq 5 \mathrm{~cm}$ & 46 & 13.0 & 50.8 & 11.5 & 0.845 \\
\hline$>5 \mathrm{~cm}$ & 141 & 11.0 & 45.6 & 10.0 & \\
\hline \multicolumn{6}{|l|}{ Tumor } \\
\hline Metastasis & 125 & 11.0 & 42.9 & 9.7 & 0.234 \\
\hline Recurrent & 49 & 12.0 & 48.1 & 12.2 & \\
\hline $\begin{array}{l}\text { Metastasis and } \\
\text { recurrent }\end{array}$ & 13 & 10.0 & 15.4 & 0 & \\
\hline \multicolumn{6}{|l|}{$\begin{array}{l}\text { Chemotherapy } \\
\text { regimens }\end{array}$} \\
\hline $\mathrm{S} 1$ & 108 & 11.0 & 43.3 & 5.9 & 0.071 \\
\hline Paclitaxel & 79 & 12.0 & 46.5 & 16.7 & \\
\hline \multicolumn{6}{|l|}{$\begin{array}{l}\text { Treatment } \\
\text { response }\end{array}$} \\
\hline $\mathrm{CR}+\mathrm{PR}$ & 67 & 16.0 & 75.5 & 26.1 & $<0.001$ \\
\hline & & & & & ontinue) \\
\hline
\end{tabular}




\begin{tabular}{cccccc}
\hline Variables & Patients (n) & Median OS (months) & 1-year OS rate (\%) & 2-year OS rate (\%) & P \\
\hline SD+PD & 120 & 10.0 & 29.9 & 2.1 & \\
NRS & & & & & \\
$<3$ & 89 & 14.0 & 57.1 & 16.8 & 0.002 \\
$\geq 3$ & 98 & 11.0 & 36.7 & 5.4 & \\
\hline
\end{tabular}

Table 4: Prognostic factors for OS by multivariate Cox regression analysis for patients with metastatic or recurrent ESCC

\begin{tabular}{lcccccc}
\hline Variables & \multicolumn{3}{c}{ Retrospective cohort } & \multicolumn{3}{c}{ Validation cohort } \\
\cline { 2 - 7 } & HR & $\mathbf{9 5 \%}$ CI & P & HR & $\mathbf{9 5 \% ~ C I ~}$ & P \\
\hline Weight loss (yes Vs no) & 0.54 & $0.31-0.94$ & 0.030 & 0.96 & $.65-1.42$ & 0.837 \\
N stage (N0 Vs N1) & 0.79 & $0.58-1.08$ & 0.144 & 0.74 & $0.51-1.07$ & 0.104 \\
Treatment response (SD+PD & 3.29 & $2.25-4.81$ & $<0.001$ & 1.51 & $1.02-2.26$ & 0.044 \\
Vs CR+PR) & 2.14 & $1.25-3.68$ & 0.006 & 1.58 & $1.07-2.34$ & 0.024 \\
NRS ( $\geq 3$ Vs $<3$ ) & & & & & & \\
\hline
\end{tabular}

Also, some nutritional parameters, such as TSF (triceps skin fold), MAC (mid-arm muscle circumference), HGS (handgrip strength) and MAMA (mid-arm muscle area), were insufficient. Therefore, we cannot compare NRS with other nutritional scores, like sPG-SGA [13].
The results of this study suggest that NRS are strongly related with BMI, weight loss and treatment response in patients with metastatic or recurrent ESCC. Additionally, NRS can be used as a possible marker to predict overall survival. Patients with NRS $\geq 3$ had an

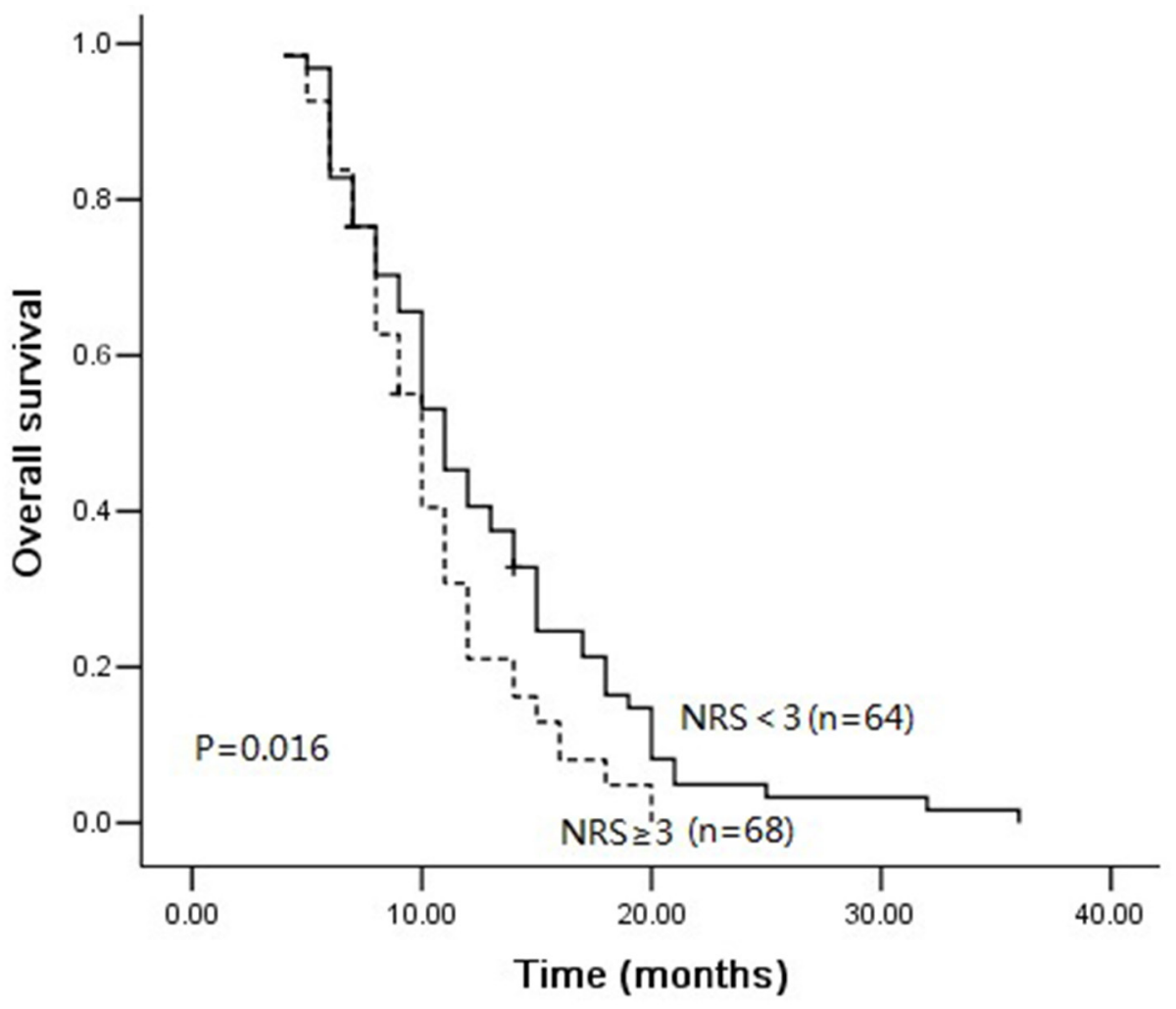

Figure 4: Overall survival curves between NRS $\geq 3$ and NRS $<3$ in validation group. 
elevated risk of death compared to those with NRS $<3$. The significance of these results merit further validation in a larger cohort of patients.

\section{MATERIALS AND METHODS}

\section{Patients}

This study in patients with metastatic or recurrent ESCC was conducted at Zhejiang cancer hospital, Hangzhou, China. A total of 187 patients were enrolled in this study. Only patients with histologically confirmed diagnosis of ESCC were included. Patients with the following characteristics were excluded from our study: patients showed a severe functional impairment of vital organs who cannot tolerate chemotherapy; those whose expectancy life less than 3 months. The nutritional status evaluation was performed by two independent investigator at the first outpatient visit after verified metastatic or recurrent ESCC diagnosis. Clinical details such as gender, age, tumor histopathology, tumor site and TNM stage were collected from hospital records. This study was approved by the institutional review board of the hospital. All patients provided informed consent before treatment.

We then used the validation cohort to test the result in predicting prognosis in patients with metastatic or recurrent ESCC. The validation cohort data were collected in the same hospital of patients who received salvage chemotherapy between October 2016 and March 2017. Finally, we identified 132 cases in the validation cohort that fit the inclusion criteria.

\section{Nutritional assessment}

Nutritional assessment was evaluated by nutrition risk score (NRS) [11, 13, 21]. NRS consisted of the combination of weight loss, body mass index (BMI), age and severity of disease. The final score ranges from 0-7. According to the previous report, NRS $\geq 3$ was considered high nutritional risk [13]. On admission to our department, the patients' height and weight were documented and detail information about weight loss was obtained using a structured questionnaire. BMI was calculated using the well-known formula. Weight loss was defined as exceeding five percent of habitual body weight in the preceding three months or ten percent in the preceding six months. Blood samples were taken from each patient routinely before treatment to measure serum albumin, hemoglobin and tumor markers (CEA, CA125 and CA199).

\section{Treatment}

Chemotherapy consisted of four to six cycles of S1 based chemotherapy or paclitaxel based chemotherapy according to patients' performance status score and their preference. If patient's PS score $=1$ or $2, \mathrm{~S} 1$ based chemotherapy was recommended, otherwise paclitaxel based chemotherapy was recommended. Chemotherapy was stopped when there was unacceptable toxicities and disease progression. Best support care (BSC) was given to all patients, including pain management, nutritional treatment, esophageal dilation or stent placement and blood product transfusions.

\section{Assessment and follow-up}

Tumor assessment was performed 6 weeks after treatment or earlier in cases of clinical suspicion of progression. The objective response to treatment was defined using the Response Evaluation Criteria in Solid Tumors (RECIST 1.1) [22]. For this analysis, patients with complete response $(\mathrm{CR})$ or partial response $(\mathrm{PR})$ were classified as responders, and those with stable disease (SD) or progressive disease (PD) were defined as nonresponders.

All patients received standardized follow-up at a 2-month interval for the first 2 years after operation, a 6-month interval in the third year and yearly thereafter. Evaluation comprised physical examination, complete blood count, chest computed tomography, esophagogram and abdominal ultrasound.

\section{Statistical analysis}

Overall survival (OS) was defined as the time interval from the initial event (diagnosis) to the death or censoring. The chi-square test was performed to evaluate the association between the clinicopathological variables and NRS. The correlations between NRS with BMI, weight loss, pretreatment albumin, pretreatment hemoglobin, pretreatment red blood cell count and tumor markers (CEA, CA125, CA199 and CA724) were estimated by linear correlation analysis. Survival curves were estimated by the univariate Kaplan-Meier method. The log-rank test was applied to check the significant differences in the curves among groups. Furthermore, we used the Cox proportional hazards model for multivariate analysis. All statistical calculations were performed with SPSS 21.0 for Windows (Chicago, IL). Two-sides P values of $<0.05$ were considered statistical significance.

\section{CONFLICTS OF INTEREST}

The authors have no financial conflicts of interest.

\section{REFERENCES}

1. Merkow RP, Bilimoria KY, Keswani RN, Chung J, Sherman KL, Knab LM, Posner MC, Bentrem DJ. Treatment trends, risk of lymph node metastasis, and outcomes for localized esophageal cancer. J Natl Cancer Inst. 2014; 106. 
2. Chau I, Norman AR, Cunningham D, Waters JS, Oates J, Ross PJ. Multivariate prognostic factor analysis in locally advanced and metastatic esophago-gastric cancer--pooled analysis from three multicenter, randomized, controlled trials using individual patient data. J Clin Oncol. 2004; 22:2395-2403.

3. Pennathur A, Gibson MK, Jobe BA, Luketich JD. Oesophageal carcinoma. Lancet. 2013; 381:400-412.

4. Jiang N, Zhao JZ, Chen XC, Li LY, Zhang LJ, Zhao Y. Clinical determinants of weight loss in patients with esophageal carcinoma during radiotherapy: a prospective longitudinal view. Asian Pac J Cancer Prev. 2014; 15:1943-1948.

5. Daly JM, Fry WA, Little AG, Winchester DP, McKee RF, Stewart AK, Fremgen AM. Esophageal cancer: results of an American College of Surgeons Patient Care Evaluation Study. J Am Coll Surg. 2000; 190:562-572; discussion 572-563.

6. Deans DA, Tan BH, Wigmore SJ, Ross JA, de Beaux AC, Paterson-Brown S, Fearon KC. The influence of systemic inflammation, dietary intake and stage of disease on rate of weight loss in patients with gastro-oesophageal cancer. Br J Cancer. 2009; 100:63-69.

7. Kubo H, Komatsu S, Ichikawa D, Kawaguchi T, Kosuga T, Okamoto K, Konishi H, Shiozaki A, Fujiwara H, Otsuji E. Impact of body weight loss on recurrence after curative gastrectomy for gastric cancer. Anticancer Res. 2016; 36:807-813.

8. Bao PP, Cai H, Peng P, Gu K, Su Y, Shu XO, Zheng Y. Body mass index and weight change in relation to triplenegative breast cancer survival. Cancer Causes Control. 2016; 27:229-236.

9. Fearon KC, Voss AC, Hustead DS; Cancer Cachexia Study Goup. Definition of cancer cachexia: effect of weight loss, reduced food intake, and systemic inflammation on functional status and prognosis. Am J Clin Nutr. 2006; 83:1345-1350.

10. Arner P, Henjes F, Schwenk JM, Darmanis S, Dahlman I, Iresjo BM, Naredi P, Agustsson T, Lundholm K, Nilsson P, Ryden M. Circulating carnosine dipeptidase 1 associates with weight loss and poor prognosis in gastrointestinal cancer. PLoS One. 2015; 10:e0123566.

11. Bachmann J, Muller T, Schroder A, Riediger C, Feith M, Reim D, Friess H, Martignoni ME. Influence of an elevated nutrition risk score (NRS) on survival in patients following gastrectomy for gastric cancer. Med Oncol. 2015; 32:204.

12. Kou F, Lu Z, Li J, Zhang X, Lu M, Zhou J, Wang X, Gong J, Gao J, Li J, Li Y, Shen L. Pretreatment lymphopenia is an easily detectable predictive and prognostic marker in patients with metastatic esophagus squamous cell carcinoma receiving first-line chemotherapy. Cancer Med. 2016; 5:778-786.
13. Orell-Kotikangas H, Osterlund P, Saarilahti K, Ravasco P, Schwab U, Makitie AA. NRS-2002 for pre-treatment nutritional risk screening and nutritional status assessment in head and neck cancer patients. Support Care Cancer. 2015; 23:1495-1502.

14. Chen KL, Liu YH, Li WY, Chen J, Gu YK, Geng QR, Jiang WQ, Huang HQ, Lin TY, Xia ZJ, Cai QQ. The prognostic nutritional index predicts survival for patients with extranodal natural killer/T cell lymphoma, nasal type. Ann Hematol. 2015; 94:1389-1400.

15. Ikeya T, Shibutani M, Maeda K, Sugano K, Nagahara H, Ohtani H, Hirakawa K. Maintenance of the nutritional prognostic index predicts survival in patients with unresectable metastatic colorectal cancer. J Cancer Res Clin Oncol. 2015; 141:307-313.

16. Cox S, Powell C, Carter B, Hurt C, Mukherjee S, Crosby TD. Role of nutritional status and intervention in oesophageal cancer treated with definitive chemoradiotherapy: outcomes from SCOPE1. Br J Cancer. 2016; 115:172-177.

17. Filip B, Scarpa M, Cavallin F, Cagol M, Alfieri R, Saadeh L, Ancona E, Castoro C. Postoperative outcome after oesophagectomy for cancer: Nutritional status is the missing ring in the current prognostic scores. Eur J Surg Oncol. 2015; 41:787-794.

18. Yamana I, Takeno S, Shibata R, Shiwaku H, Maki K, Hashimoto T, Shiraishi T, Iwasaki A, Yamashita Y. Is the geriatric nutritional risk index a significant predictor of postoperative complications in patients with esophageal cancer undergoing esophagectomy? Eur Surg Res. 2015; 55:35-42.

19. Peng J, Cai J, Niu ZX, Chen LQ. Early enteral nutrition compared with parenteral nutrition for esophageal cancer patients after esophagectomy: a meta-analysis. Dis Esophagus. 2016; 29:333-341.

20. Yang JS, Wang T, Qiu MQ, Li QL. Comparison of efficacy and toxicity profiles between paclitaxel/ lobapoatin- and cisplatin/5-fluorouracil-based concurrent chemoradiotherapy of advanced inoperable oesophageal cancer. Int Med J. 2015; 45:757-761.

21. Kondrup J, Rasmussen HH, Hamberg O, Stanga Z, Ad Hoc EW. Nutritional risk screening (NRS 2002): a new method based on an analysis of controlled clinical trials. Clin Nutr. 2003; 22:321-336.

22. Eisenhauer EA, Therasse P, Bogaerts J, Schwartz LH, Sargent D, Ford R, Dancey J, Arbuck S, Gwyther S, Mooney M, Rubinstein L, Shankar L, Dodd L, et al. New response evaluation criteria in solid tumours: revised RECIST guideline (version 1.1). Eur J Cancer. 2009; 45:228-247. 